\title{
The role of altered sympathetic nervous system activity in the pathogenesis of obesity
}

\author{
BY ERIC RAVUSSIN AND PIETRO ANTONIO TATARANNI \\ Clinical Diabetes and Nutrition Section, National Institute of Diabetes and Digestive and \\ Kidney Diseases, National Institutes of Health, 4212 North 16th Street, Rm 541, \\ Phoenix, Arizona 85016, USA
}

Obesity and its complications are highly prevalent in industrialized countries. In the United States, obesity affects one in three individuals and its incidence continues to increase despite numerous campaigns to reduce it (Kuczmarski et al. 1994). In 1986, the US public health cost related to obesity was 36 billion dollars (Colditz, 1992). To prevent future increases in these health and social costs, we need to uncover the causes of the epidemic of obesity, which affects both industrialized countries and countries in transition from a rural to an urban lifestyle.

Obesity is determined by both genetic and environmental factors. Whereas adoption and twin studies indicate that much of the variability in body size and body composition is attributable to genetic factors (Stunkard et al. 1990), migration studies and studies of the prevalence of obesity in different populations living in a similar environment indicate an important role for environmental factors (Ravussin et al. 1994). As an example of the possible effects of exposure of a population to the rapid environmental changes, recent studies have shown that, despite a substantial reduction in total energy intake in the UK over the past three decades, the prevalence of obesity has continued to rise, implying that increased fat intake and decreased physical activity are probably the two major factors causing this epidemic of obesity (Prentice \& Jebb, 1995).

Over the past decade we have identified metabolic risk factors for body-weight gain. In prospective studies in Pima Indians, a population with a high prevalence of obesity (Knowler et al. 1991), four metabolic factors which are known to have a familial component have been found to predict body-weight gain. These are: a low 'relative' resting metabolic rate (Ravussin et al. 1988), a low level of spontaneous physical activity (Zurlo et al. 1992), a high 24 h RQ (Zurlo et al. 1990; i.e. a low fat:carbohydrate oxidation ratio) and high insulin sensitivity (Swinburn et al. 1991). We also suggest that low sympathetic nervous system activity may be a risk factor for body-weight gain in human subjects (Spraul et al. 1993).

The sympathetic nervous system (SNS) and the adrenal medullae represent major physiological regulators of body homeostasis. The SNS regulates the cardiovascular system and blood pressure by controlling both cardiac output and vascular resistance. The SNS also has an important role in regulating body temperature, some digestive secretions in the gastrointestinal tract, respiratory function and pupillary dilation. Finally, the SNS has effects on endocrine organs such as the pancreas and the adipose tissue thus affecting fuel partitioning and mobilization. In the present short review we will present evidence that the SNS may also be involved in the regulation of body weight.

\section{METHODS TO ASSESS SYMPATHETIC NERVOUS SYSTEM ACTIVITY}

Over the past several years, different techniques have been used to assess the activity of the 
SNS in man. These include: (1) plasma noradrenaline concentration, (2) pharmacological receptor blockade/stimulation, (3) urinary noradrenaline excretion, (4) noradrenaline turnover, (5) microneurography and (6) some more indirect methods such as heart-rate spectral analysis and pupillometry. All these methods have been used to assess possible differences in SNS activity between lean and obese subjects. Among these six methods mentioned previously, it seems that the two best methods are urinary noradrenaline excretion and microneurography. Indeed, plasma concentrations of noradrenaline have been difficult to assess due to the acute effect of the stress of venipuncture. Pharmacological receptor blockade and stimulation studies provide only crude, indirect measurements of SNS activity. Finally, noradrenaline turnover studies necessitate the infusion of radioactive tracers with measurements under steady-state conditions which are often not easy to achieve.

\section{SYMPATHETIC NERVOUS SYSTEM ACTIVITY AND OBESITY}

Numerous studies have investigated possible differences in SNS activity between lean and obese subjects. In a mini-review, Young \& Macdonald (1992) have summarized the studies published between 1980 and 1992 comparing plasma and urinary levels of noradrenaline and adrenaline in lean and obese human subjects. Of thirty-two reports comparing plasma concentration and urinary excretion of noradrenaline in lean and obese subjects, fourteen studies showed impaired activity of the SNS in obese subjects, nineteen studies showed no difference, and eleven showed enhanced SNS activity in the obese. It is important to remember, however, that many factors other than obesity may contribute to the variability in SNS activity and may confound the results. These include gender, age, antecedent diet, blood pressure, glucose tolerance, hormone concentrations, physical activity, and body fat distribution. Therefore, the inconsistency in the previously mentioned studies may be partially explained by differences in experimental design and subject selection. The inconsistency of the results also indicates the importance of controlling, as much as possible, for these confounding factors when studying SNS activity.

Indirect measurements of SNS activity, such as variation in cardiac R-R intervals and pupillometry, originally indicated that obese subjects have depressed SNS activity (Peterson et al. 1988). Despite the wide scientific recognition of such studies, there is now growing evidence that obese subjects have increased SNS activity (Spraul et al. 1993; Sherrer et al. 1994; Poehlman et al. 1995; Jones et al. 1996). Using direct measurements of SNS activity by microneurography, we showed that independently of age, muscle sympathetic nerve activity was increased in direct proportion to body fat (Spraul et al. 1993). These results were confirmed in a study of Swiss volunteers (Sherrer et al. 1994). Furthermore, we recently showed that the lower activity observed in women ( $\mathrm{Ng}$ et al. 1993; Jones et al. 1996) is mostly related to their lower waist:thigh ratio, i.e. lesser central obesity (Jones et al. 1996; see Fig. 1). The relationship between SNS activity (plasma noradrenaline appearance rate) and central adiposity was also shown in young and old men (Poehlman et al. 1995). Taken together, these findings suggest that an accumulation of total and central body fat is associated with higher SNS activity.

\section{SYMPATHETIC NERVOUS SYSTEM ACTIVITY AND ENERGY EXPENDITURE}

Low energy expenditure has been shown to precede body-weight gain in infants (Roberts 


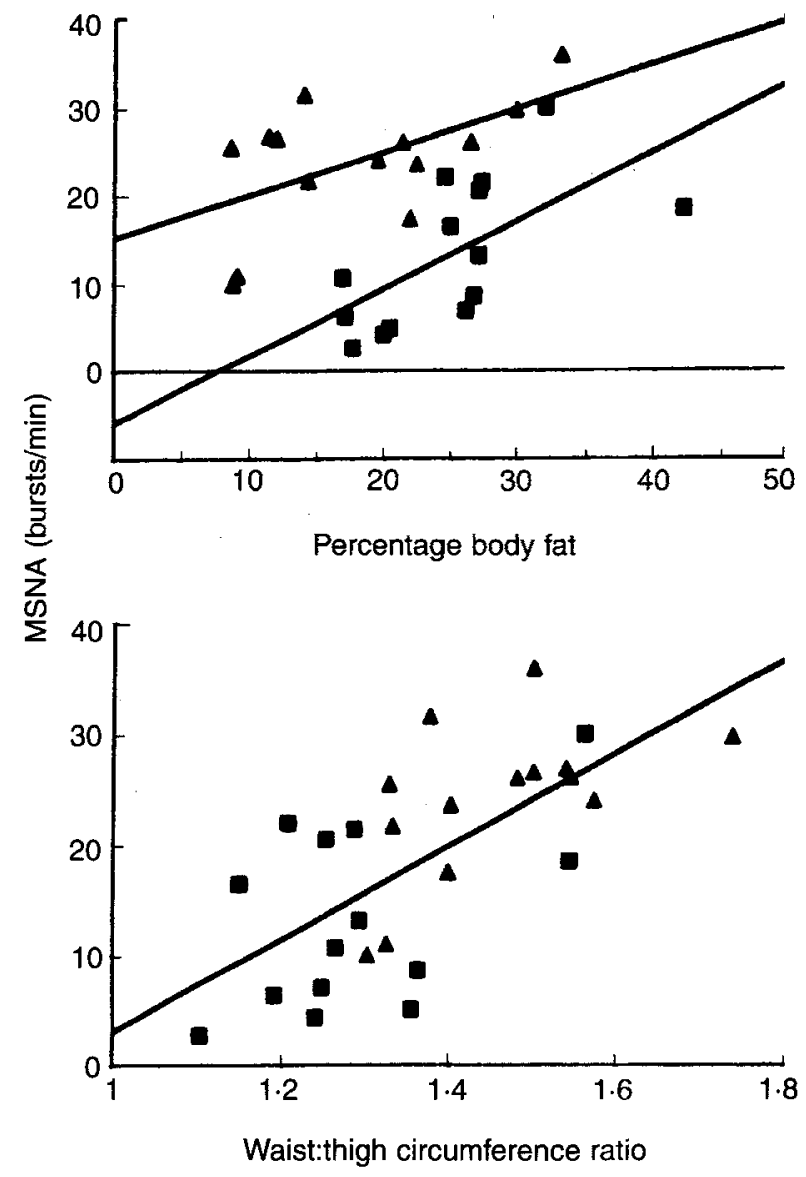

Fig. 1. Relationship between muscle sympathetic nerve activity (MSNA) measured by microneurography and (a) percentage body fat and (b) waist:thigh circumference ratio. Note that at any given percentage of body fat MSNA is lower in females $(\boldsymbol{\square})$ compared with males $(\mathbf{A})$. However, MSNA $\boldsymbol{v}$. body fat distribution shows no difference between males and females. (Adapted from Jones et al. 1996.)

et al. 1988), children (Griffiths et al. 1990) and adults (Ravussin et al. 1988). There is now ample evidence that the physiological tone of the sympathoadrenal system plays an important role in the regulation of energy expenditure. Stimulation of the SNS activity by sympathomimetic compounds such as ephedrine not only reduces energy intake but also increases energy expenditure. Sympathomimetic drugs seem to act both at a central level and at the periphery by activation of beta adrenoreceptors.

Sympathetic nervous system activity and resting metabolic rate (RMR)

Recent studies of SNS activity provide evidence that some of the variability in RMR is associated with the variability in SNS activity. Beta blockade causes a decrease in RMR in some but not all populations (Saad et al. 1991). The magnitude of the beta-blockadeinduced decrease in RMR is related to the initial value of the RMR (Saad et al. 1991). Longer-term administration of beta blockers, however, does not decrease metabolic rate but 
does inhibit lipolytic activity and fat oxidation (Acheson et al. 1988), another risk factor for body-weight gain. In addition, when SNS outflow is reduced by clonidine, RMR is decreased (Schwartz et al. 1988). Noradrenaline turnover studies have shown that most of the variability in RMR unexplained by body size and body composition is related to differences in SNS activity (Poehlman et al. 1994; Toth \& Poehlman, 1994). A similar association was found between the variability in RMR and the variability in muscle sympathetic nerve activity (Spraul et al. 1993). Taken together, these studies indicate that SNS activity does modulate RMR, the largest component of daily energy expenditure (Table 1).

\section{Sympathetic nervous system activity and the thermic effect of food}

Although the thermic effect of food accounts for only $10 \%$ of daily energy expenditure, many researchers believe that a low thermic effect of food plays a role in the development of obesity. It has been shown that some variability in the thermic effect of food is accounted for by SNS activity. A few years ago, Acheson (1993) reviewed the possible influence of the autonomic nervous system on nutrient-induced thermogenesis. Schwartz et al. (1987, 1990) using noradrenaline kinetics showed that the increased SNS activity in response to a meal accounts for at least part of the meal-induced thermogenesis. Studies using betablockade have shown that the facultative component of glucose-induced thermogenesis is sympathetically mediated (Acheson et al. 1984). The major drive for the increase in SNS activity in response to a meal seems to be insulin (Rowe et al. 1981; Anderson et al. 1991; Spraul et al. 1994). Despite the clear impact of SNS activity on thermogenesis, it is unlikely that such modulation accounts for large amounts of energy deficit. In fact, the variability in the thermic effect of food is not related to body-weight changes (Tataranni et al. 1995).

\section{Sympathetic nervous system activity and spontaneous physical activity}

It is clear that physical activity and exercise increase SNS activity. However, it is not known whether the physiological variability in SNS activity is related to the level of free-living physical activity. Only one study performed in a respiratory chamber showed that noradrenaline appearance rate, adjusted for differences in body size, correlated with spontaneous physical activity (Christin et al. 1993; Fig. 2). These results suggest that SNS

Table 1. Correlations between measurements of sympathetic nervous system (SNS) activity and resting metabolic rate (RMR) adjusted for fat-free mass, fat mass and age in Caucasians and Pima Indians* (From Saad et al. 1991; Spraul et al. 1993)

\begin{tabular}{lllc}
\hline \hline SNS assessment & \multicolumn{1}{c}{ Caucasians } & Pima Indians \\
\hline B-Blockade $\dagger$ & $r-0.57(P<0.001)$ & NS \\
Urinary NA excretion & $r 0.78(P<0.0001)$ & NS \\
Muscle SNS activity & $r 0.51(P<0.05)$ & NS \\
\hline \hline
\end{tabular}

NA, noradrenaline.

* Pima Indians have low levels of sympathetic nervous activity, and unlike in Caucasians, RMR does not correlate with SNS activity. Also $\beta$-blockade causes a decrease in RMR in Caucasians, but not in Pima Indians:

$\dagger$ Correlation between change in RMR in response to propanolol infusion and initial adjusted RMR. 


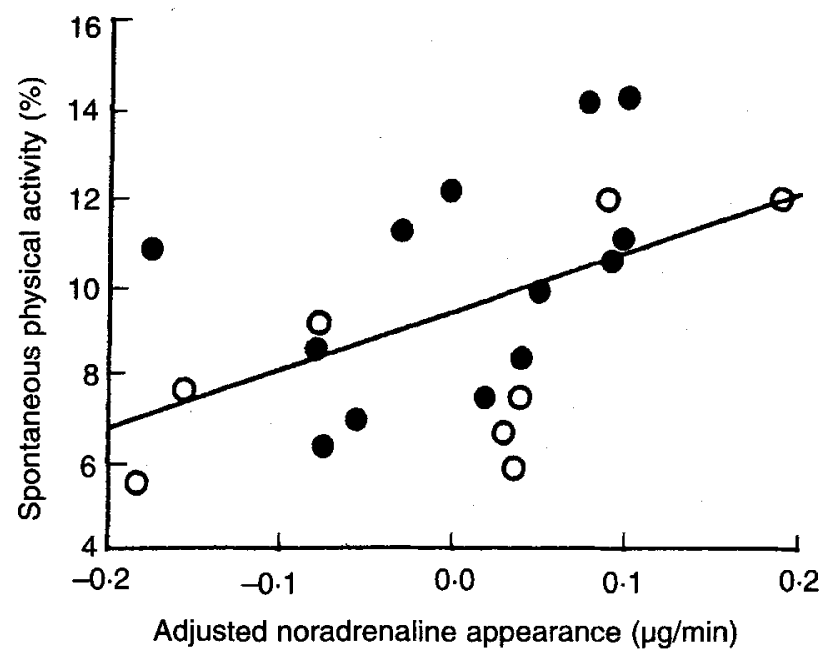

Fig. 2. Relationship between spontaneous physical activity measured by radar during the 24 h energy expenditure measurement and noradrenaline production rate adjusted for differences in body surface area (residuals of a regression between noradrenaline production rate and body surface area; $r 0.50, P<0.03)$. ( $($ ), Pima Indian men ( $n$ 13); (O), white men ( $n$ 8). (Reproduced from Christin et al. 1993.)

activity is a determinant of the level of spontaneous physical activity (or fidgeting), a component of daily energy expenditure which can account for a significant amount of energy (0.4-3.3 MJ/d). In summary, SNS activity seems to affect all three major components of daily energy expenditure and, therefore, low SNS activity can play a role in the development of obesity.

\section{SYMPATHETIC NERVOUS SYSTEM ACTIVITY AND FOOD INTAKE}

Experimental studies in animals have shown a reciprocal relationship between food intake and the activity of the SNS. Almost two decades ago Young \& Landsberg $(1977 a, b)$ showed that an increase in food intake leads to increased SNS activity, while starvation is accompanied by a reduction in the function of the autonomic system. These findings have been confirmed in several other studies and it has been suggested that the meal-induced increased SNS activity is mediated by plasma insulin levels (Welle et al. 1981; Schwartz et al. 1985; Berne et al. 1989). Indeed, insulin per se increases SNS activity during a hyperinsulinaemic-euglycaemic clamp procedure (Rowe et al. 1981; Anderson et al. 1991). Much more variability is observed in the reduction of SNS activity in response to food deprivation. Diuresis and the consequent plasma volume losses often associated with energy restriction tend in fact to increase the release of catecholamines to maintain a stable blood pressure (Leiter et al. 1984). However, a decrease in SNS activity has been reported consistently in those studies in which enough $\mathrm{Na}$ was provided to prevent plasma volume depletion (Jung et al. 1979; DeHaven et al. 1980; Sowers et al. 1982). Some of these studies also indicate that the decrease in SNS activity in response to starvation might be independent of the decrease in plasma insulin (Welle \& Feldman, 1986). Taken together these findings suggest that SNS activity responds to changes in food intake and mediates 
changes in energy expenditure to buffer energy surfeits or deficits.

In studies of the effects of diurnal changes in SNS activity on eating Sakaguchi et al. (1988) noticed that in rodents low SNS activity precedes the increase in food intake. They, therefore, proposed the hypothesis that the relationship between SNS activity and food intake could be of the feedback type, i.e. low SNS activity driving food intake, and high SNS activity decreasing food intake. Recently, and for the first time in human subjects, Raben et al. (1996) showed an inverse relationship between the postprandial suppression of hunger and the noradrenaline response induced by the meal, suggesting that endogenous sympathetic activation in response to food may inhibit hunger. Indeed, several peptides and drugs can induce opposite changes in SNS activity and food intake. For example, enterostatin selectively decreases fat intake in animals eating a high-fat diet while increasing SNS activity (Bray, 1993), whereas galanin stimulates food intake and decreases SNS activity (Tempel \& Liebowitz, 1990). In human subjects the administration of glucocorticoids has been shown to induce a decrease in SNS activity and an increase in food intake (Tataranni et al. 1996a). However, there are exceptions to the generalization that experimental manoeuvres which increase SNS activity reduce food intake and vice versa (Bray, 1991). Lesions of the paraventricular nucleus of the hypothalamus have no effect on SNS activity but induce increased food intake and obesity (Tokunaga et al. 1986). Cold exposure induces both increased SNS activity and food intake (Young et al. 1982). Therefore, changes in SNS activity and food intake may possibly be associated but without a cause-and-effect relationship. A more tenable and current view is that the same central pathways that regulate SNS activity also influence feeding behaviour and that autonomic activity and food intake are coordinately regulated in the control of energy balance (Kaiyala et al. 1995).

Until new data clarify the mechanism of the relationship between SNS and food intake, we are left with the notion that low SNS activity possibly represents an indicator of a metabolic status favouring storage rather than depletion of energy.

\section{SYMPATHETIC NERVOUS SYSTEM ACTIVITY AND WEIGHT GAIN}

Animal studies seem to suggest that low SNS activity predisposes to, and is associated with, obesity. In rodents with hypothalamic obesity (lesions of the ventromedial hypothalamus), the firing rate of sympathetic nerves to the brown adipose tissue is reduced in the basal state (Niijima et al. 1984) and in response to food intake (Sakaguchi \& Bray, 1987) and/or cold exposure (Niijima et al. 1984). SNS activity has been found also to be markedly reduced in genetically-obese rodents, such as the $o b / o b$ mouse and the $f a / f a$ rat. As a result of low SNS activity in these animals, energy expenditure is reduced and food intake is increased, leading to positive energy balance and, therefore, body-weight gain starting at a very young age (Knehans \& Romsos, 1983; Levin et al. 1983). A new study, however, questions the idea that low SNS activity from birth is the only explanation for the development of obesity in $f a / f a$ rats (Kortner et al. 1994). In fact, in these animals, body weight increased even in the presence of artificially-elevated SNS activity throughout their first 3 weeks of life.

Very little information on SNS activity and weight gain is available in humans. Pima Indians have low SNS activity compared with weight-matched Caucasians suggesting that the SNS may play a role in the development of obesity in this population (Spraul et al. 


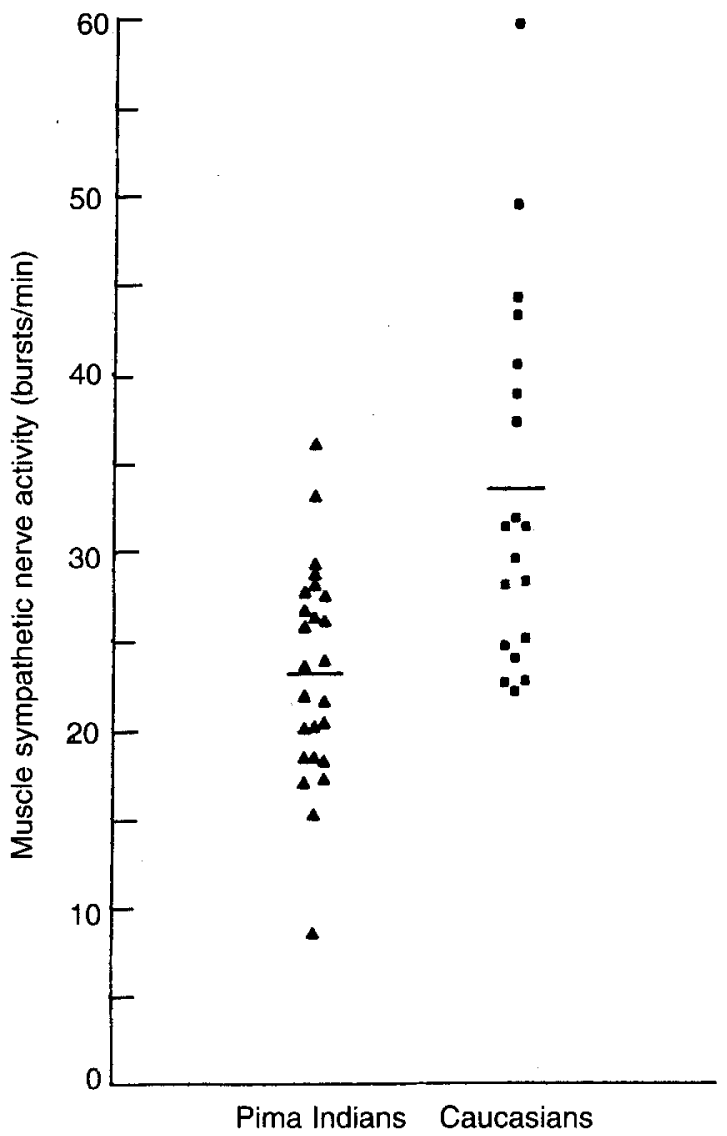

Fig. 3. Sympathetic nervous system activity measured directly by microneurography in twenty-five Pima Indian men and nineteen weight-matched Caucasian men. Muscle sympathetic nerve activity was lower in Pima Indians (23 (SD 6) bursts/min) compared with Caucasians (33 (SD 10) bursts/min; $P=0.0007$ ). (Reproduced from Spraul et al. 1993.)

1993). As previously reviewed (Young \& Macdonald, 1992), large inconsistencies are found in the literature when comparing SNS and/or adrenal medullary function of lean and obese subjects. Moreover, these studies are of little value in understanding the role of the SNS or adrenal medullae in the aetiology of obesity, since cross-sectional data cannot indicate whether differences in sympathoadrenal function are the cause or the result of obesity. A more informative approach is provided by studies in post-obese subjects. However, results from such studies are contradictory as well. Astrup et al. (1992) reported larger plasma noradrenaline concentrations $(50 \%)$ and $24 \mathrm{~h}$ energy expenditure $(8 \%)$ in post-obese women as compared with weight-matched controls. This is in line with a report from Amatruda et al. (1993), but in contrast to a study from Geissler et al. (1987) which showed reduced $24 \mathrm{~h}$ energy expenditure in post-obese subjects. To really understand whether low SNS activity is the cause or the consequence of obesity, it is necessary to study the SNS before weight gain, i.e. in pre-obese subjects. The only data are in a recent report from our laboratory suggesting that low SNS activity is associated with body-weight gain 
and accumulation of central adipose tissue in Pima Indians (Tataranni et al. 1996b). Additional longitudinal studies will help in our understanding of the contribution of the autonomic nervous system to the aetiology of obesity.

\section{REFERENCES}

Acheson, K. J. (1993). Influence of autonomic nervous system on nutrient-induced thermogenesis in humans. Nutrition 9, 373-380.

Acheson, K. J., Ravussin, E., Schoeller, D. A., Christin, L., Bourquin, L., Baertschi, P., Danforth, E. \& Jéquier, E. (1988). Two-week stimulation or blockade of the sympathetic nervous system in man: Influence on body weight, body composition, and twenty-four-hour energy expenditure. Metabolism 37, 91-98.

Acheson, K. J., Ravussin, E., Wahren, J. \& Jéquier, E. (1984). Obligatory and facultative thermogenesis. Journal of Clinical Investigation 70, 1570-1580.

Amatruda, J. M., Statt, M. C. \& Welle, S. L. (1993). Total and resting energy expenditure in obese women reduced to ideal body weight. Journal of Clinical Investigation 92, 1236-1242.

Anderson, E. A., Hoffman, R. P., Balon, T. W., Sinkey, C. A. \& Mark, A. L. (1991). Hyperinsulinemia produces both sympathetic neural activation and vasodilation in normal humans. Journal of Clinical Investigation 87, 2246-2252.

Astrup, A., Beumann, B., Christensen, N. J. \& Madsen, J. (1992). 24-Hour energy expenditure and sympathetic activity in post obese women consuming a high-carbohydrate diet. American Journal of Physiology 262, E282-E288.

Berne, C., Fagius, J. \& Niklasson, F. (1989). Sympathetic response to oral carbohydrate administration. Journal of Clinical Investigation 84, 1403-1409.

Bray, G. A. (1991). Reciprocal relation between the sympathetic nervous system and food intake. Brain Research Bulletin 27, 517-520.

Bray, G. A. (1993). The nutrient balance hypothesis: peptides, sympathetic activity, and food intake. Annals of the New York Academy of Sciences 676, 223-241.

Christin, L., O'Connell, M., Bogardus, C., Danforth, E. Jr \& Ravussin, E. (1993). Norepinephrine turnover and energy expenditure in Pima Indian and White Men. Metabolism 42, 723-729.

Colditz, G. A. (1992). Economic cost of obesity. American Journal of Clinical Nutrition 55, 503S-507S.

DeHaven, J., Sherwin, R., Hendler, R. \& Felig, P. (1980). Nitrogen and sodium balance and sympatheticnervous-system activity in obese subjects treated with a low-calorie protein or mixed diet. New England Journal of Medicine 302, 477-482.

Geissler, C. A., Miller, D. S. \& Shah, M. (1987). The daily metabolic rate of the post-obese and the lean. American Journal of Clinical Nutrition 45, 914-929.

Griffiths, M., Payne, P. R., Stunkard, A. J., Rivers, J. P. W. \& Cox, M. (1990). Metabolic rate and physical development in children at risk of obesity. Lancet 336, 76-77.

Jones, P. P., Spraul, M., Matt, K. S., Seals, D. R., Skinner, J. S. \& Ravussin, E. (1996). Gender does not influence sympathetic neural reactivity to stress in healthy humans. American Journal of Physiology 270, H350-H357.

Jung, R. T., Shetty, P. S., Barrand, M., Callingham, B. A. \& James, W. P. T. (1979). Role of catecholamines in hypotensive response to dieting. British Medical Journal 1, 12-13.

Kaiyala, K. J., Woods, S. C. \& Schwartz, M. W. (1995). New model for the regulation of energy balance and adiposity by the central nervous system. American Journal of Clinical Nutrition 62, 1123S-1134S.

Knehans, A. W. \& Romsos, D. R. (1983). Norepinephrine turnover in obese (ob/ob) mice - effects of age, fasting, and acute cold. American Journal of Physiology 244, E567-E574.

Knowler, W. C., Pettitt, D. J., Saad, M. F., Charles, M. A., Nelson, R. G., Howard, B. V., Bogardus, C. \& Bennett, P. H. (1991). Obesity in Pima Indians: Its magnitude and relationship with diabetes. American Journal of Clinical Nutrition 53, 1543S-1551S.

Kortner, G., Petrova, O., Vogt, S. \& Schmidt, I. (1994). Sympathetically and nonsympathetically mediated onset of excess fat deposition in Zucker rats. American Journal of Physiology 267, E947-E953.

Kuczmarski, R. J., Flegal, K. M., Campbell, S. M. \& Johnson, C. L. (1994). The increasing prevalence of overweight among US adults. The National Health and Nutrition Examination Surveys. Journal of the American Medical Association 272, 205-211.

Leiter, L. A., Grose, M., Yale, J.-F. \& Marliss, E. B. (1984). Catecholamine responses to hypocaloric diets and fasting in obese human subjects. American Journal of Physiology 247, E190-E197. 
Levin, B. E., Triscari, J. \& Sullivan, A. C. (1983). Relationship between sympathetic activity and diet-induced obesity in two rat strains. American Journal of Physiology 245, R367-R371.

Ng, A. V., Callister, R., Johnson, D. G. \& Seals, D. R. (1993). Age and gender influence muscle sympathetic nerve activity at rest in healthy humans. Hypertension 21, 498-503.

Niijima, A., Rohner-Jenrenaud, F. \& Jenrenaud, B. (1984). Role of ventrohypothalamus on sympathetic efferents of brown adipose tissue. American Journal of Physiology 247, R650-R654.

Peterson, H. R., Rothschild, M., Weinberg, C., Fell, R. D., McLeish, K. R. \& Pfeifer, M. A. (1988). Body fat and the activity of the autonomic nervous system. New England Journal of Medicine 318, 1077-1083.

Poehlman, E. T., Arciero, P. J. \& Goran, M. I. (1994). Endurance exercise in aging humans: effects on energy metabolism. Exercise Sports Science Review 22, 251-284.

Poehlman, E. T., Gardner, A. W., Goran, M. I., Arciero, P. J., Toth, M. J., Ades, P. A. \& Calles-Escandon, J. (1995). Sympathetic nervous system activity, body fatness, and body fat distribution in younger and older males. Journal of Applied Physiology 78, 802-806.

Prentice, A. M. \& Jebb, S. A. (1995). Obesity in Britain: gluttony or sloth? British Medical Journal 311, 437-439.

Raben, A., Holst, J. J., Christensen, N. J. \& Astrup, A. (1996). Determinants of postprandial appetite sensations: macronutrient intake and glucose metabolism. International Journal of Obesity 20, 161-169.

Ravussin, E., Lillioja, S., Knowler, W. C., Christin, L., Freymond, D., Abbott, W. G. H., Boyce, V., Howard, B. V. \& Bogardus, C. (1988). Reduced rate of energy expenditure as a risk factor for body-weight gain. New England Journal of Medicine 318, 467-472.

Ravussin, E., Valencia, M. E., Esparza, J., Bennett, P. H. \& Schulz, L. O. (1994). Effects of a traditional lifestyle on obesity in Pima Indians. Diabetes Care 17, 1067-1074.

Roberts, S. B., Savage, J., Coward, W. A., Chew, B. \& Lucas, A. (1988). Energy expenditure and intake in infants born to lean and overweight mothers. New England Journal of Medicine 318, 461-466.

Rowe, J. W., Young, J. B., Minaker, K. L., Stevens, A. L., Pallotta, J. \& Landsberg, L. (1981). Effect of insulin and glucose infusions on sympathetic nervous system activity in normal man. Diabetes 30, 219-225.

Saad, M. F., Alger, S. A., Zurlo, F., Young, J. B., Bogardus, C. \& Ravussin, E. (1991). Ethnic differences in sympathetic nervous system mediated energy expenditure. American Journal of Physiology 261, E789-E794.

Sakaguchi, T. \& Bray, G. A. (1987). The effect of intrahypothalamic injections of glucose on sympathetic efferent firing rate. Brain Research Bulletin 18, 591-595.

Sakaguchi, T., Takahashi, M. \& Bray, G. A. (1988). Diurnal changes in sympathetic activity; relation to food intake and to insulin injected into the ventromedial ${ }_{i}$ and suprachiasmatic nucleus. Journal of Clinical Investigation 32, 282-286.

Schwartz, R. S., Jaeger, L. F., Silberstein, S. \& Veith, R. C. (1987). Sympathetic nervous system activity and the thermic effect of feeding in man. International Journal of Obesity 11, 141-149.

Schwartz, R. S., Jaeger, L. F. \& Veith, R. C. (1988). Effect of clonidine on the thermic effect of feeding in humans. American Journal of Physiology 254, R90-R94.

Schwartz, R. S., Jaeger, L. F. \& Veith, R. C. (1990). The thermic effect of feeding in older men: The importance of the sympathetic nervous system. Metabolism 39, 733-737.

Schwartz, R. S., Ravussin, E., Massari, M., O'Connell, M. \& Robbins, D. C. (1985). The thermic effect of carbohydrate versus fat feeding in man. Metabolism 34, 285-293.

Sherrer, U., Randin, D., Tappy, L., Vollenweider, P., Jéquier, E. \& Nicod, P. (1994). Body fat and sympathetic nerve activity in healthy subjects. Circulation 89, 2634-2640.

Sowers, J. R., Nyby, M., Stern, N., Beck, F., Baron, S., Catania, R. \& Vlachis, N. (1982). Blood pressure and hormone changes associated with weight reduction in obese. Hypertension 4, 686-691.

Spraul, M., Anderson, E. A., Bogardus, C. \& Ravussin, E. (1994). Muscle sympathetic nerve activity in response to glucose ingestion. Impact of plasma insulin and body fat. Diabetes 43, 191-196.

Spraul, M., Ravussin, E., Fontvieille, A. M., Rising, R., Larson, D. E. \& Anderson, E. A. (1993). Reduced sympathetic nervous activity. A potential mechanism predisposing to body weight gain. Journal of Clinical Investigation 92, 1730-1735.

Stunkard, A. J., Harris, J. R., Pederson, N. L. \& McClearn, G. E. (1990). The body mass index of twins who have been reared apart. New England Journal of Medicine 322, 1483-1487.

Swinburn, B. A., Nyomba, B. L., Saad, M. F., Zurlo, F., Raz, I., Knowler, W. C., Lillioja, S., Bogardus, C. \& Ravussin, E. (1991). Insulin resistance associated with lower rates of weight gain in Pima Indians. Journal of Clinical Investigation 88, 168-173. 
Tataranni, P. A., Larson, D. E., Snitker, S., Flatt, J. P., Young, J. B. \& Ravussin, E. (1996a). The effects of glucocorticoids on energy metabolism and food intake in humans. American Journal of Physiology 271, E317-E325.

Tataranni, P. A., Larson, D. E., Snitker, S. \& Ravussin, E. (1995). Thermic effect of food in humans: methods and results from use of a respiratory chamber. American Journal of Clinical Nutrition 61, 1013-1019.

Tataranni, P. A., Young, J. B. \& Ravussin, E. (1996b). A low sympathetic nervous system activity is associated with body weight gain in Pima Indians. International Journal of Obesity 20, Suppl. 4, 63.

Tempel, D. L. \& Liebowitz, S. F. (1990). Diurnal variations in the feeding responses to norepinephrine, neuropeptide Y and galanin in the PVN. Brain Research Bulletin 25, 821-825.

Tokunaga, K., Fukushma, M., Kemnitz, J. W. \& Bray, G. A. (1986). Comparison of ventromedial and paraventricular lesions in rats that become obese. American Journal of Physiology 251, R1221-R1227.

Toth, M. J. \& Poehlman, E. T. (1994). Sympathetic nervous system activity and resting metabolic rate in vegetarians. Metabolism 43, 621-625.

Welle, S. \& Feldman, J. (1986). Effect of glucose and fat feeding on norepinephrine turnover in rats. Journal of Neural Transmission 67, 67-75.

Welle, S., Lilavivat, U. \& Campbell, R. G. (1981). Thermic effect of feeding in man: increased plasma norepinephrine levels following glucose but not protein or fat consumption. Metabolism 30, 953-958.

Young, J. B. \& Landsberg, L. (1977a). Suppression of sympathetic nervous system during fasting. Science 196, 1473-1475.

Young, J. B. \& Landsberg, L. (1977b). Stimulation of the sympathetic nervous system during sucrose feeding. Nature 269, 615-617.

Young, J. B. \& Macdonald, I. A. (1992). Sympathoadrenal activity in human obesity: heterogeneity of findings since 1980. International Journal of Obesity 16, 959-967.

Young, J. B., Saville, M. E., Rothwell, N. J., Stock, M. J. \& Landsberg, L. (1982). Effect of diet and cold exposure on norepinephrine turnover in brown adipose tissue of rat. Journal of Clinical Investigation 69, $1061-1071$.

Zurlo, F., Ferraro, R. T., Fontvieille, A. M., Rising, R., Bogardus, C. \& Ravussin, E. (1992). Spontaneous physical activity and obesity: cross-sectional and longitudinal studies in Pima Indians. American Journal of Physiology 263, E296-E300.

Zurlo, F., Lillioja, S., Esposito-Del Puente, A., Nyomba, B. L., Raz, I., Saad, M. F., Swinburn, B. A., Knowler, W. C., Bogardus, C. \& Ravussin, E. (1990). Low ratio of fat to carbohydrate oxidation as predictor of weight gain: study of 24-h RQ. American Journal of Physiology 259, E650-E657. 